\title{
Antibacterial activity and cytotoxicity of multi-walled carbon nanotubes decorated with silver nanoparticles
}

This article was published in the following Dove Press journal:

International Journal of Nanomedicine

30 September 2014

Number of times this article has been viewed

\section{Youngmin Seo' \\ Jangsun Hwang' \\ Jieun Kim' \\ Yoon Jeong ${ }^{1-3}$ \\ Mintai P Hwang ${ }^{3}$ \\ Jonghoon Choi ${ }^{1,2}$}

'Department of Bionano Technology, Graduate School, Hanyang University, Seoul, Korea; ${ }^{2}$ Department of Bionano Engineering, Hanyang University ERICA, Ansan, Korea; ${ }^{3}$ Center for Biomaterials, Korea Institute of Science and Technology, Seoul, Korea

Correspondence: Jonghoon Choi Department of Bionano Engineering, Hanyang University ERICA, 55 Hanyangdaehak-ro, Sangnok-gu, Ansan-si 426-79I, Korea

$\mathrm{Tel}+82314005203$

Fax +82314368146

Email jonghchoi@hanyang.ac.kr
Abstract: Recently, various nanoscale materials, including silver (Ag) nanoparticles, have been actively studied for their capacity to effectively prevent bacterial growth. A critical challenge is to enhance the antibacterial properties of nanomaterials while maintaining their biocompatibility. The conjugation of multiple nanomaterials with different dimensions, such as spherical nanoparticles and high-aspect-ratio nanotubes, may increase the target-specific antibacterial capacity of the consequent nanostructure while retaining an optimal biocompatibility. In this study, multi-walled carbon nanotubes (MWCNTs) were treated with a mixture of acids and decorated with Ag nanoparticles via a chemical reduction of $\mathrm{Ag}$ cations by ethanol solution. The synthesized Ag-MWCNT complexes were characterized by transmission electron microscopy, X-ray diffractometry, and energy-dispersive X-ray spectroscopy. The antibacterial function of Ag-MWCNTs was evaluated against Methylobacterium spp. and Sphingomonas spp. In addition, the biocompatibility of Ag-MWCNTs was evaluated using both mouse liver hepatocytes (AML 12) and human peripheral blood mononuclear cells. Finally, we determined the minimum amount of Ag-MWCNTs required for a biocompatible yet effective antibacterial treatment modality. We report that $30 \mu \mathrm{g} / \mathrm{mL}$ of Ag-MWCNTs confers antibacterial functionality while maintaining minimal cytotoxicity toward both human and animal cells. The results reported herein would be beneficial for researchers interested in the efficient preparation of hybrid nanostructures and in determining the minimum amount of Ag-MWCNTs necessary to effectively hinder the growth of bacteria.

Keywords: antimicrobial, nanoconstructs, toxicity

\section{Introduction}

Bioaerosols - a suspension of airborne particles, contain living organisms such as viruses, bacteria, and fungi and comprise a significant portion of the air we breathe. Consequently, small amounts of bacteria in the bioaerosol can attach to wet surfaces and form biofilms, ${ }^{1}$ which further enhance the growth of more bacteria and generate a foul odor. Furthermore, biofilms have been shown to be responsible for chronic infectious diseases in animals and humans. ${ }^{2}$ In particular, Methylobacterium spp. and Sphingomonas spp. bacterial colonies and biofilms are commonly observed in areas with abundant moisture that are not regularly cleaned, such as the heat-transferring units in air conditioners or shower rooms. While chemicals or antibiotic chemical compounds (eg, chlorine, phenol, penicillin, cephalosporin) have been commonly utilized to remove such biofilms or bacteria, their toxicity and the development of antibiotic resistance necessitates the development of alternate remedies for the successful eradication of harmful bacteria and the prevention of biofilm formation. 
One such approach is utilizing the antibacterial property of silver. Widely recognized for its capacity to kill bacteria, researchers and companies alike have long incorporated its use in various applications. Specifically, the lack of cytotoxicity to mammalian cells has resulted in its use in antibacterial and antibiotic treatments for a long time. Furthermore, silver has been used as an effective water-disinfecting material for silverwares. ${ }^{3}$ The use of the antibiotic capacity of silver has also been expanded to the field of biotechnology and bioscience for research in various fields, such as osteoimplantation, inflammation, burns treatment, drug delivery, and biochips. ${ }^{4}$

In particular, an enhanced level of antibacterial properties observed in nanoscale silver materials has led to increased interest in the application of silver nanomaterials in biomedical research. ${ }^{5,6}$ While development in fronts such as nanoscale synthesis has resulted in an increase in the surface-to-volume ratio of silver nanoparticles and, consequently, their antibacterial activity, ${ }^{7-9}$ the mechanism behind the antibacterial property of silver remains unclear. Explanations include the production of reactive oxygen species that causes membrane damage, the degradation of cell membranes by pits due to physical contact, and dephosphorylation of key peptides in cell signaling pathways, yet a conclusive mechanism remains elusive due to contradictory findings. ${ }^{10}$ Consequently, while the antibacterial activity of silver nanoparticles have led to their promotion for use in medical devices and various other products, their potential effects have resulted in regulatory measures from the United States Environmental Protection Agency (USEPA) in an effort to address uncontrolled usage of nanoparticles in specific forms. ${ }^{11}$

In order to resolve this issue, we hypothesized that the integration of silver nanoparticles into multi-walled carbon nanotubes (MWCNTs) would provide maximal antibacterial properties and minimal biotoxicity. Since MWCNTs have a high aspect ratio, given their nanoscale diameter and microscale length, their large surface area is adequate for the deposition of mass quantities of molecules during water filtration/disinfection. Additionally, a relatively light weight, high tensile strength, excellent electrical conductivity, and chemical and thermal stability are some of the unique properties of carbon nanotubes when compared to other carbon families such as diamond and charcoal. ${ }^{12}$ Furthermore, both single-walled carbon nanotubes and MWCNTs have been reported to have antibacterial activity; ${ }^{13}$ although the antibacterial activity of MWCNTs is inferior to that of single-walled carbon nanotubes, the economical advantages of MWCNTs are superior.
In this study, we combined silver nanomaterials with MWCNTs and expected to see a synergistic increase in antibacterial activity against Methylobacterium spp. and Sphingomonas spp. bacteria. By loading silver nanoparticles onto nanotubes, we anticipated that the resulting AgMWCNTs could be optimized for minimal absorption into the body or excretion into the environment. Furthermore, while previous reports on the preparation of Ag-MWCNTs detail a lengthy synthesis protocol with many complicated steps, ${ }^{14-17}$ we replaced the usage of environmentally hazardous reductants (eg, $\mathrm{NaBH}_{4}$, formamide, dimethyloformamide, or hydrazine) with ethyl alcohol for a simplified protocol. Using our modified protocol, we decreased the synthesis duration and minimized MWCNT degradation during the transformation of Ag ions to Ag nanoparticles on the surface of the nanotubes. Finally, following characterization of the prepared Ag-MWCNTs, we determined a minimum amount of Ag-MWCNTs required to prevent the growth of Methylobacterium spp. and Sphingomonas spp. while maintaining biocompatibility to mammalian cells.

\section{Experimental methods Acid treatment of MWCNTs}

MWCNTs (40-60 nm in diameter, 5-15 $\mu \mathrm{m}$ in length) were purchased from Tokyo Chemical Industry Co., LTD., (Tokyo, Japan). Thirty milligrams of the MWCNTs were immersed in a 3:1 (vol/vol) mixture of $\mathrm{H}_{2} \mathrm{SO}_{4}$ and $\mathrm{HNO}_{3}$, and then subsequently sonicated for 1 hour to produce acidified carbon nanotubes (MWCNTs-COOH). Oxidized nanotubes were later washed with deionized water until the $\mathrm{pH}$ of the washing buffer reached seven.

\section{Decoration of silver nanoparticles onto MWCNTs}

Ten milligrams of MWCNTs-COOH and $2 \mathrm{~mL}$ of $0.1 \mathrm{M}$ silver nitrate solutions were each dispersed in $6 \mathrm{~mL}$ of ethanol and sonicated for 1 hour. The solutions were then mixed and sonicated for 1 hour to decorate the silver nanoparticles onto the MWCNTs. The resulting Ag-MWCNT samples were washed with deionized water and dried under a vacuum at $120^{\circ} \mathrm{C}$ overnight.

\section{Characterization}

The Ag-MWCNTs were characterized by transmission electron microscopy (TEM), X-ray diffraction (XRD), and energy-dispersive X-ray spectroscopy (EDS). XRD patterns of the products were recorded on a Rigaku D/MAX 2500 (Tokyo, Japan) using $\mathrm{Cu} \mathrm{K} \alpha$ photon source (40 kV, $100 \mathrm{~mA}$ ). 
TEM and high-resolution TEM images were obtained using a JEOL (Tokyo, Japan) JEM-2100F microscope equipped with an EDS detector at an acceleration voltage of $200 \mathrm{kV}$. The TEM and EDS samples were prepared by drying a droplet of the Ag-MWCNT suspension on 300 mesh-size carbon film-coated copper grid.

\section{Antibacterial tests}

The antibacterial activity of the Ag-MWCNTs was evaluated against Methylobacterium spp. (Korea Collection for Type Cultures Daejeon Korea 12618, Daejeon, Korea) and Sphingomonas spp. (KCTC 12898) bacteria. One-hundredmicroliter volumes of each type of bacteria were inoculated in R2A broth (MBcell, Los Angeles, CA, USA) and subsequently incubated with untreated control, methanol, 1,000 $\mu \mathrm{g}$ / mL MWCNTs-COOH, $50 \mu \mathrm{g} / \mathrm{mL}$ Ag-MWCNTs, $40 \mu \mathrm{g} / \mathrm{mL}$ Ag-MWCNTs, $30 \mu \mathrm{g} / \mathrm{mL}$ Ag-MWCNTs, or $20 \mu \mathrm{g} / \mathrm{mL} \mathrm{Ag-}$ MWCNTs. After incubation under shaking conditions (180 $\mathrm{rpm})$ at $30^{\circ} \mathrm{C}$ for 32 hours, $100 \mu \mathrm{L}$ duplicate samples of decimal dilutions were spread on R2A agar (MBcell) plates. After incubation at $30^{\circ} \mathrm{C}$ for 48 hours, the colonies on the plates were counted. All experiments were performed in triplicate.

\section{Zone of inhibition test}

The zone of inhibition assay on agar plates was used to determine the inhibition zone of Ag-MWCNTs against Methylobacterium spp. (KCTC 12618) and Sphingomonas spp. (KCTC 12898) bacteria. Samples were cut into paper discs and then placed on R2A plates previously inoculated with $100 \mu \mathrm{L}$ of inoculum containing approximately $10^{7}-10^{8}$ $\mathrm{CFU} \mathrm{mL} \mathrm{m}^{-1}$ of cultured bacteria. The plates were incubated at $30^{\circ} \mathrm{C}$ for 48 hours and then the diameters of the inhibition zones around the Ag-MWCNTs were determined.

\section{Cytotoxicity test}

The effects of Ag-MWCNTs on the viability of mouse liver hepatocytes (AML 12; Chungnam University, Daejeon Korea) and human peripheral blood mononuclear cells (PBMCs) (American Type Culture Collection [ATCC], Manassas, VA, USA) were evaluated using a trypan blue exclusion assay and a LIVE/DEAD ${ }^{\circledR}$ Viability/Cytotoxicity Kit. Cultured AML 12 cells and human PBMCs were plated in six-well plates $\left(1 \times 10^{5}\right.$ cells per well $)$ in Dulbecco's Modified Eagle's Medium (DMEM) and Roswell Park Memorial Institute medium (RPMI), respectively, each supplemented with $10 \%(\mathrm{v} / \mathrm{v})$ fetal bovine serum and $1 \%$ sterile antibiotic. The cells were cultured at $37^{\circ} \mathrm{C}$ in a humidified atmosphere of $5 \% \mathrm{CO}_{2} / 95 \%$ air for $8-12$ hours. Subsequently, untreated control, methanol or dimethyl sulfoxide (DMSO), and 30 or $40 \mu \mathrm{g} / \mathrm{mL}$ Ag-MWCNTs, were added to the cells in a serumfree medium and cultured for 4-8 hours. Results are quantified as relative values to that of the negative control, where the negative control (untreated) is set to $100 \%$ viability. All experiments were performed in triplicate.

\section{Statistical analysis}

One-tailed Mann-Whitney $U$-test were performed using GraphPad Prism (v 5 for Mac OS X; GraphPad Software, Inc., La Jolla, CA, USA).

\section{Results and discussion}

Figure 1 summarizes the preparation of Ag-MWCNTs and the evaluation of their antibacterial activities. Treatment of MWCNTs with an acid mixture of $\mathrm{H}_{2} \mathrm{SO}_{4}$ and $\mathrm{HNO}_{3}$ produced oxygen-containing functional groups (eg, $\mathrm{OH}$, $\mathrm{C}=\mathrm{O}, \mathrm{COOH}$ ) with nominal damage to the structure of the nanotubes. ${ }^{18}$ Silver nanoparticles were subsequently formed on the functional groups of the nanotubes via a reduction of Ag ions by ethanol. ${ }^{19}$ Specifically, oxygen-containing functional groups on the MWCNTs-COOH provided nucleation sites for both the homing of $\mathrm{Ag}$ ions and growth of evenly distributed Ag nanoparticles. ${ }^{20}$ Indeed, the silver nanoparticles on the MWCNTs were well dispersed and evenly distributed on the surfaces of the MWCNTs as assessed by TEM (Figure 2A-C). EDS element analysis of Ag-MWCNTs indicated that approximately $1.43 \%$ (weight percent) of the total analysis area could be attributed to Ag, presumably corresponding to the Ag nanoparticles on the Ag-MWCNTs (Figure 2D); the presence of copper, chromium, and tantalum elements could be attributed to the use of 300 mesh-sized copper grids coated with carbon film. ${ }^{17}$ Silicon present in the sample may have originated from impurities included in TEM substrates or from artifacts during sample preparation. ${ }^{17,21,22}$ In addition, structural validation of the Ag and carbon nanomaterials was assessed via examination of Ag-MWCNTs and MWCNTs-COOH XRD patterns, which indicate two major diffraction peaks at $2 \theta=26.1^{\circ}$ and $42.6^{\circ}$ in the (002) and (110) planes, respectively (Figure 2E). The broad diffraction peak of the (002) plane can be correlated with the structural ordering of MWCNT, ${ }^{23}$ while diffraction peaks observed at $2 \theta=38.08^{\circ}, 44.3^{\circ}, 64.46^{\circ}$, and $77.36^{\circ}$ correlate to the (111), (200), (220), and (311) planes, respectively - all standard features for a face-centered cubic silver crystalline structure. ${ }^{22}$ Finally, the average diameter of the Ag nanoparticles was approximately $4.97 \pm 0.84 \mathrm{~nm}$ as assessed via TEM (Figure 2F). Overall, TEM, XRD, and EDS results confirm 

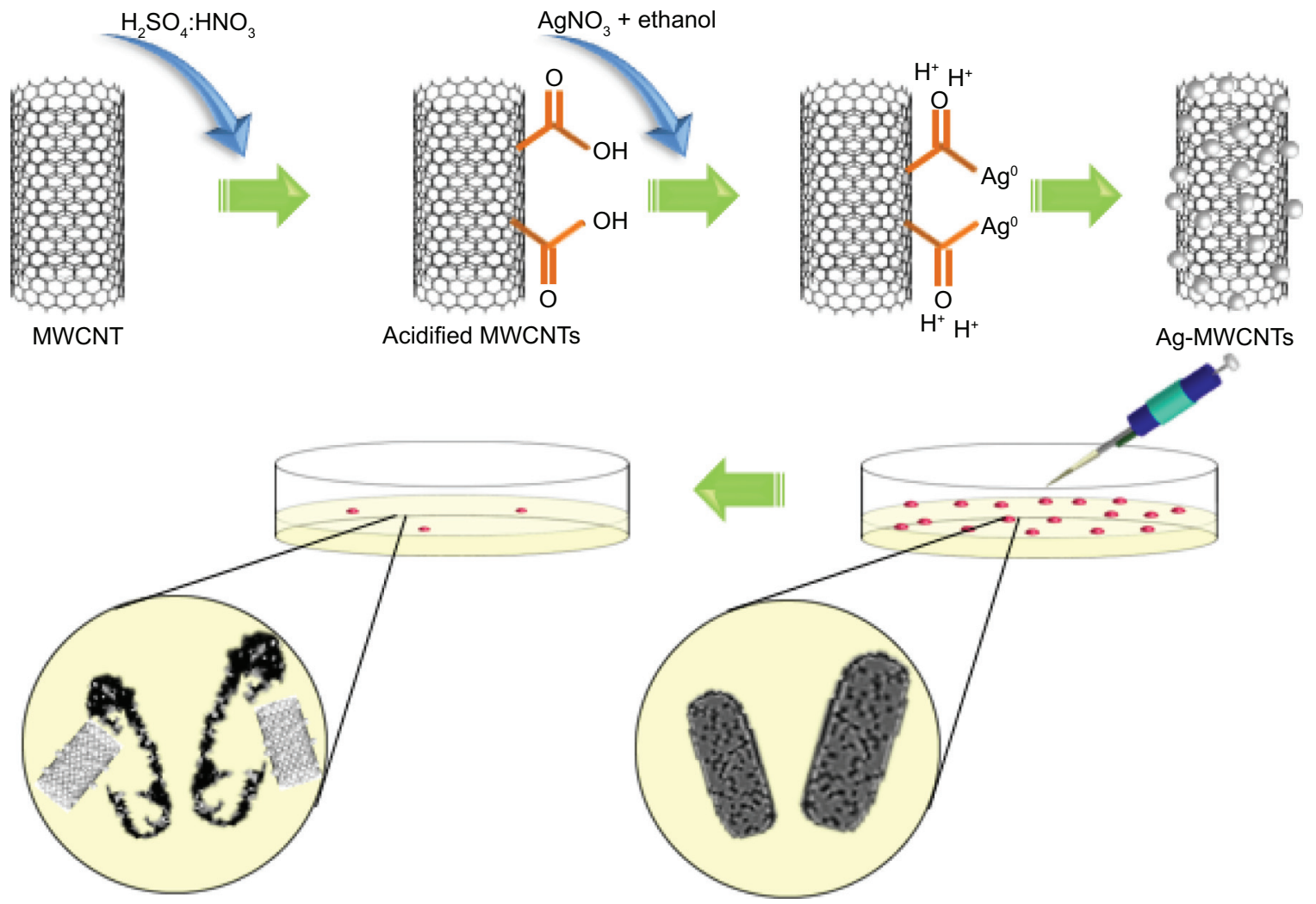

Figure I Schematic diagram of Ag-MWCNTs' preparation and evaluation of their antibacterial activity. Abbreviation: MWCNT, multi-walled carbon nanotube.

the production of monodispersed silver nanoparticles well distributed over the entire surface of the MWCNTs.

Recent studies evaluating the antibacterial potential of silver nanomaterials and silver-containing products have shown these to be particularly effective against Escherichia coli. ${ }^{21,24-26}$ In particular, Methylobacterium spp. and Sphingomonas spp. are the most abundant bacteria and promote biofilm formation on heat exchangers or any other surface that is difficult to clean on a regular basis. Consequently, these bacteria and biofilms, which can cause chronic diseases and an overpowering stench, are a good model for evaluating the antibacterial properties of Ag-MWCNTs. An overall summary of the antibacterial activity of Ag-MWCNTs against Methylobacterium spp. and Sphingomonas spp. is described in Figure 3A. Specifically, untreated control, methanol (a positive control), MWCNTs-COOH $(1,000 \mu \mathrm{g} / \mathrm{mL})$, and various concentrations of Ag-MWCNTs (50, 40, 30, and $20 \mu \mathrm{g} / \mathrm{mL}$ ) were evaluated for their antibacterial activity by measuring the cell concentration $(\mathrm{CFU} / \mathrm{mL})$ after an incubation step and a 48 -hour culture step on agar plates. In the negative control, Methylobacterium spp. and Sphingomonas spp. had an average of $4 \times 10^{9}$ and $1 \times 10^{8}$ colonies, respectively, while the positive control only contained $6 \times 10^{6}$ and $7 \times 10^{4}$ colonies, respectively. MWCNTs with - $\mathrm{COOH}$ groups have been reported to have $30 \%-50 \%$ killing efficiencies against Bacillus subtilis, Staphylococcus aureus, or E. coli using a concentration of $3 \mathrm{mg} / \mathrm{mL} \cdot{ }^{13,27}$ Based on the previous studies, we inferred that $1 \mathrm{mg} / \mathrm{mL}$ of MWCNT-COOHs would exhibit approximately $1 \%-10 \%$ killing efficiency against bacteria, which happens to be similar to that observed in the negative control. A similar number of colonies as that of the positive control were registered in groups with 20 or $30 \mu \mathrm{g} / \mathrm{mL}$ of Ag-MWCNTs. On the other hand, no colonies were observed in groups with 40 or $50 \mu \mathrm{g} / \mathrm{mL}$ Ag-MWCNTs. In subsequent studies, $30 \mu \mathrm{g} / \mathrm{mL}$ Ag-MWCNTs was selected as an optimal concentration of Ag-MWCNTs, in which a statistically higher killing efficiency against both Methylobacterium spp. and Sphingomonas spp. was observed compared to that of the positive control. Since our goal was to find a minimum concentration of Ag-MWCNTs required to eradicate both types of bacteria abundant in biofilms, we chose $30 \mu \mathrm{g} / \mathrm{mL}$ as the optimal concentration of Ag-MWCNTs.

In order to confirm the antibacterial activity of Ag-MWCTs in static conditions, we measured the inhibition zone for each experimental group containing bacteria cultured in ample nutrient conditions on R2A agar plates (Figure 3B and C). 

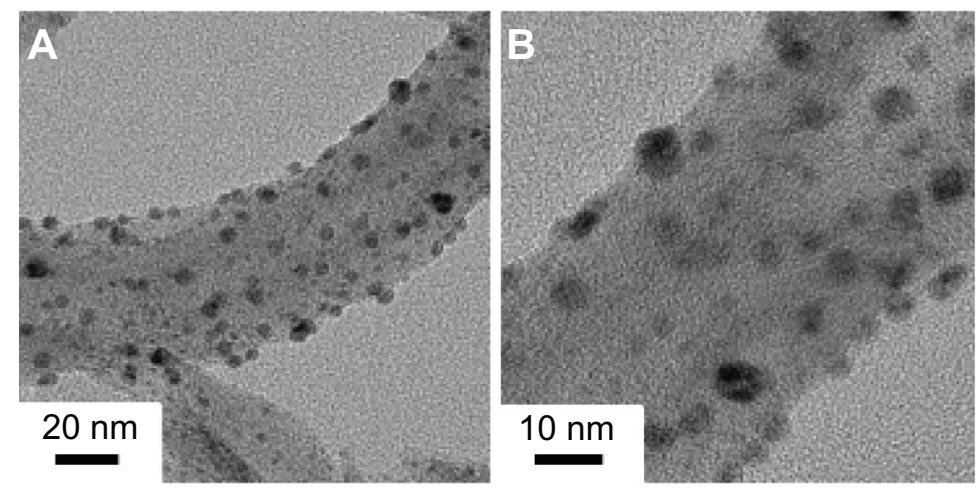

D
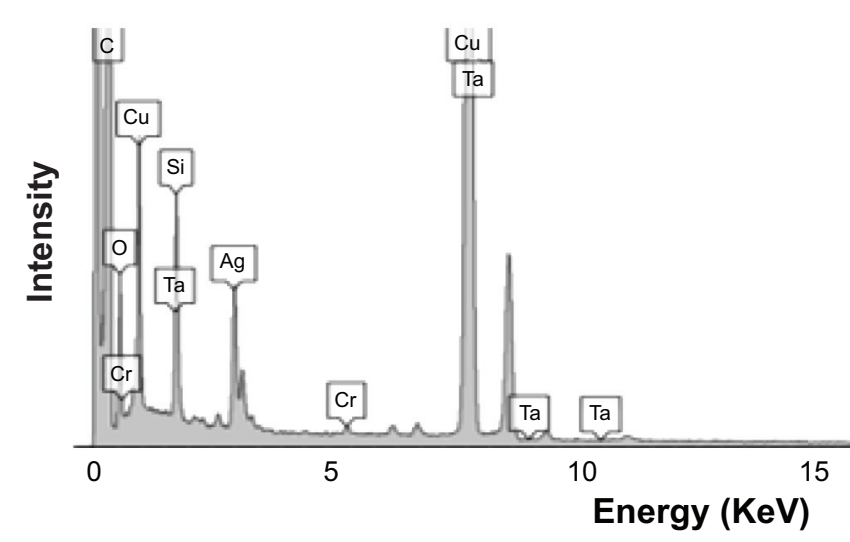
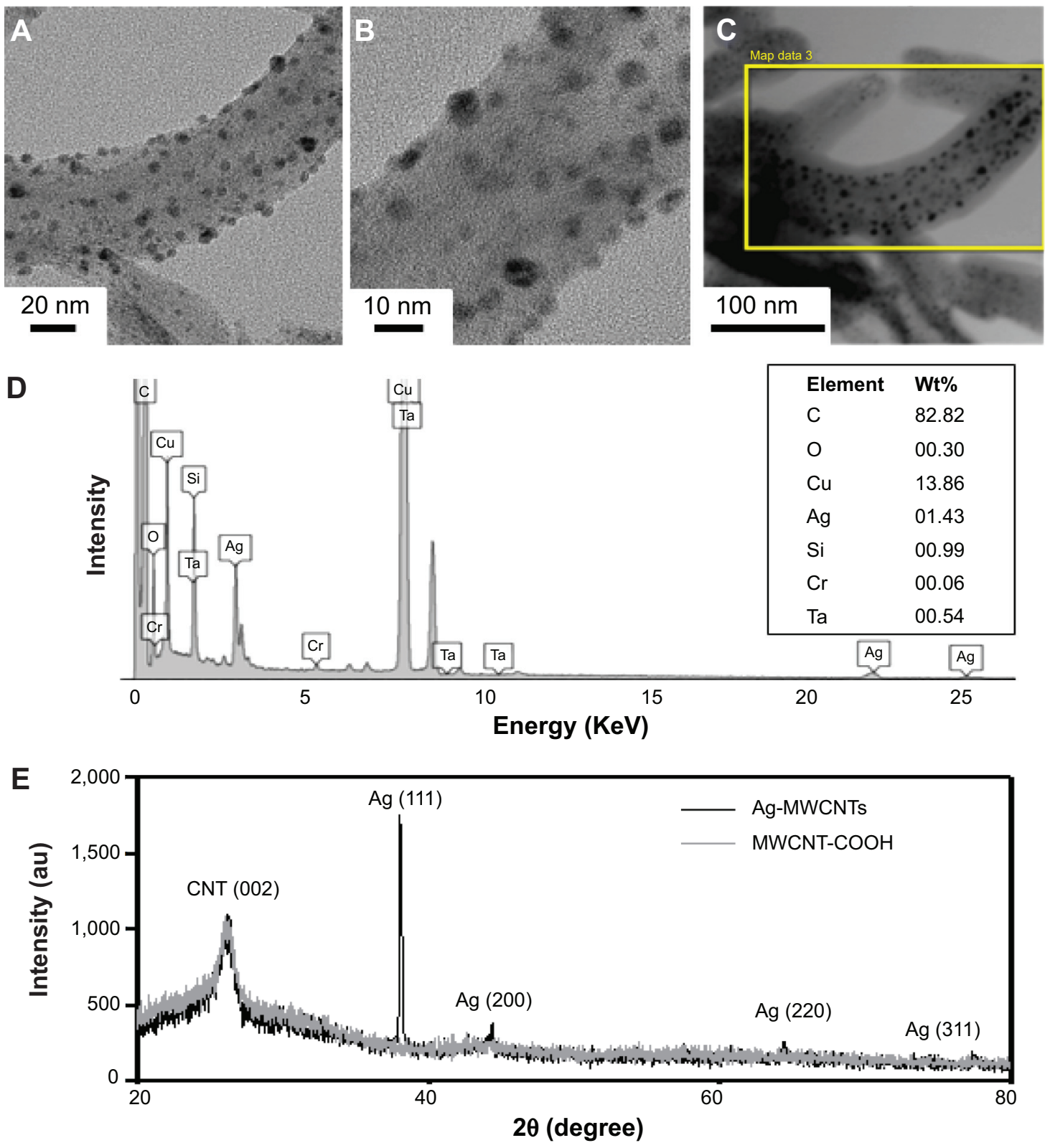

F

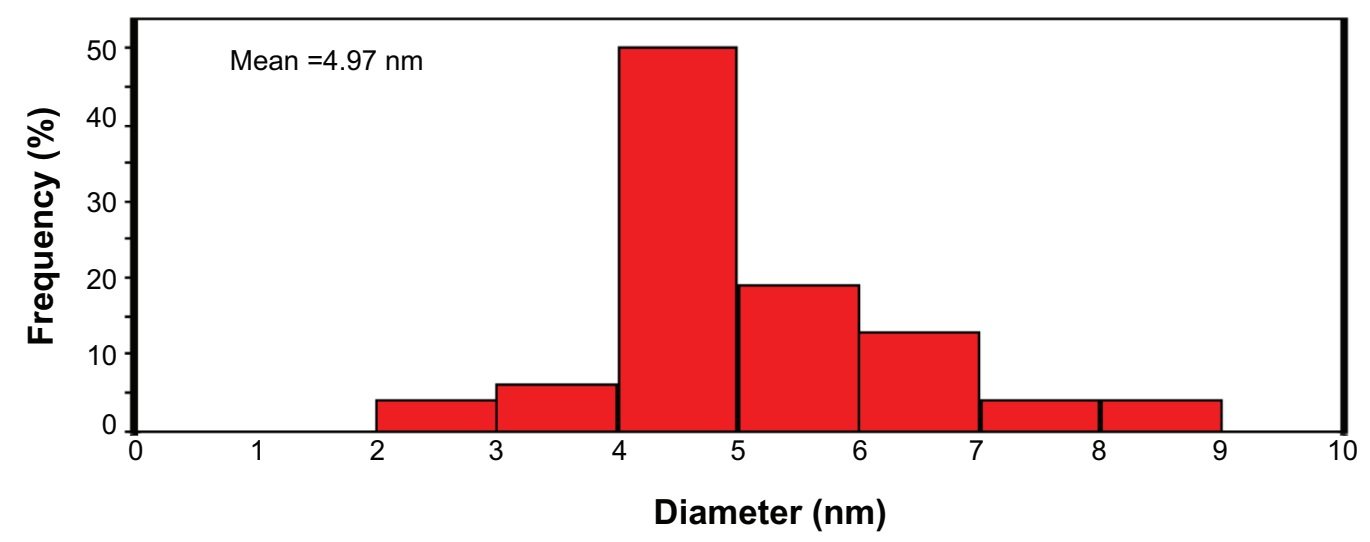

Figure 2 Physicochemical characterization of Ag-MWCNTs.

Notes: (A and B) TEM images of MWCNTs decorated with Ag nanoparticles. (C) EDS element map and pattern (yellow box is the area chosen for EPS analysis), and (D) EDS element analysis of Ag-MWCNTs. (E) XRD pattern of Ag-MWCNTs and Acidified MWCNTs. (F) Size distribution of Ag nanoparticles as assessed via TEM ( $n=100$ ). Abbreviations: CNT, carbon nanotube; EDS, energy-dispersive X-ray spectroscopy; MWCNT, multi-walled CNT; TEM, transmission electron microscopy; XRD, X-ray diffraction. 


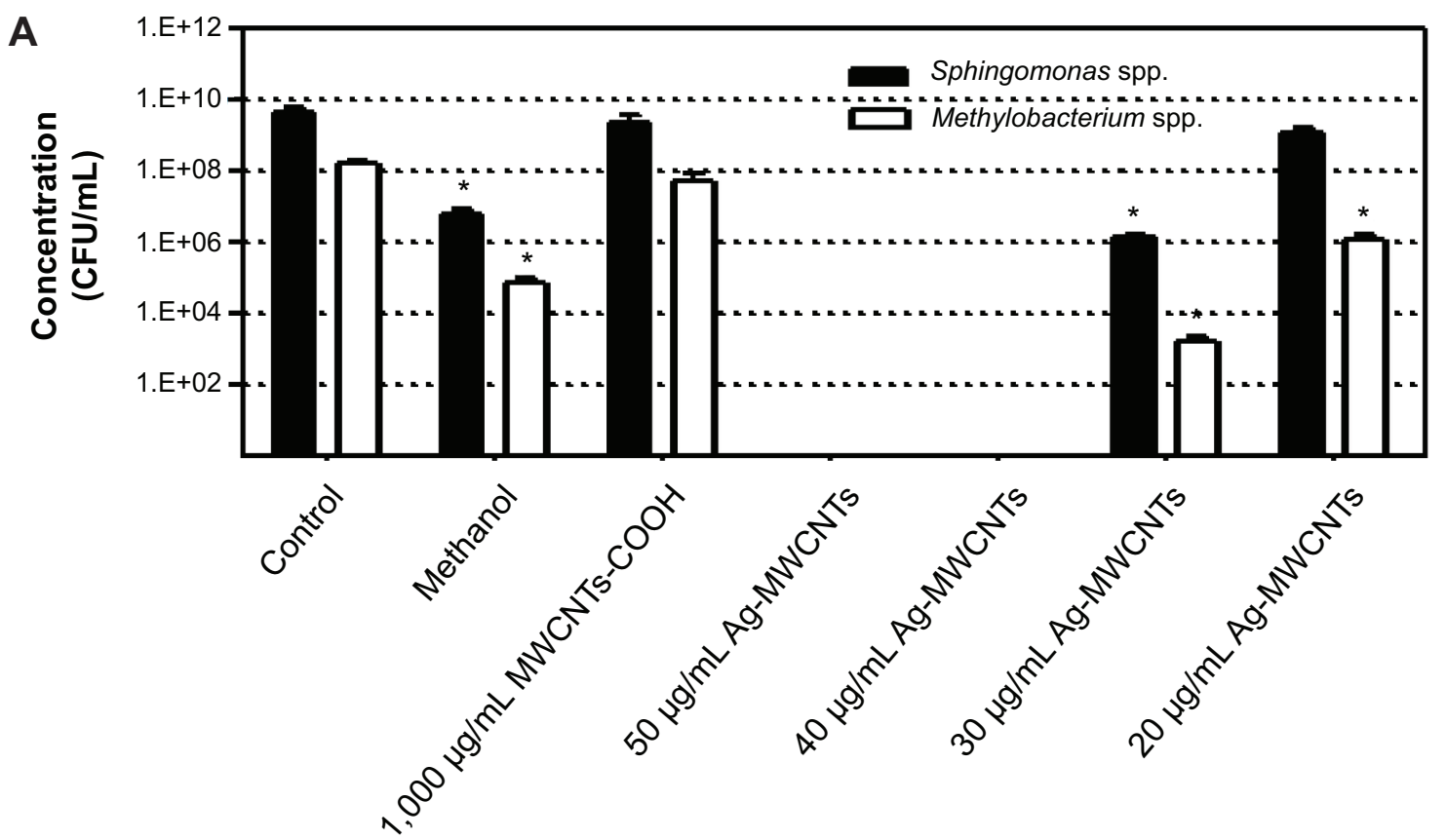

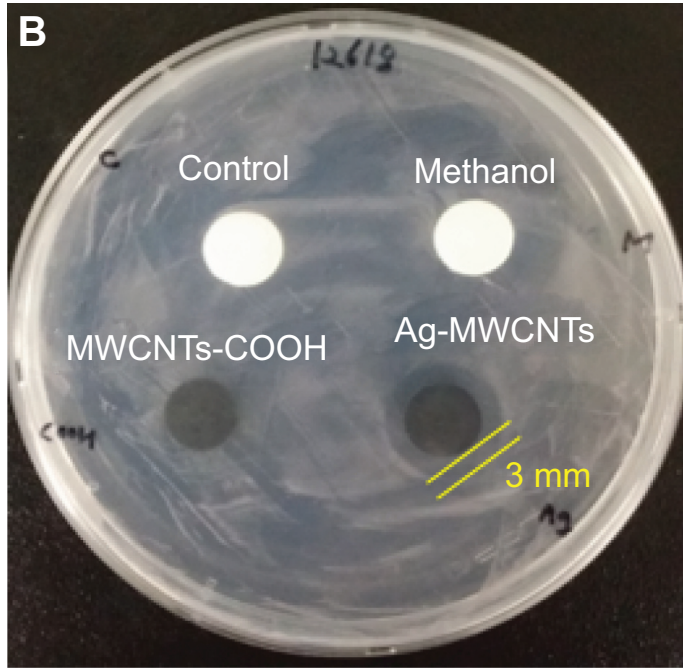

Methylobacterium spp.

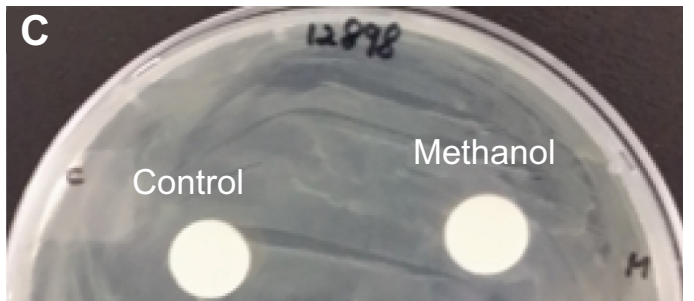

Ag-MWCNTs

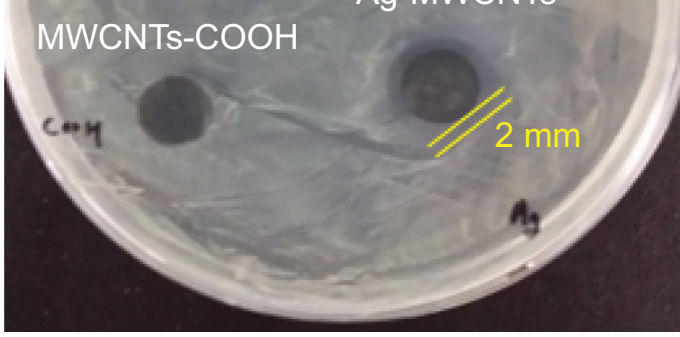

Sphingomonas spp.

Figure 3 Antibacterial evaluation of Ag-MWCNTs.

Notes: (A) Antibacterial activity of different samples against Sphingomonas spp. and Methylobacterium spp. Concentration (CFU/mL): $* P<0.05$, one-tailed Mann-Whitney U-test. Data are representative of three experiments. (B) Evaluation of inhibition zones by different samples for Methylobacterium spp. and (C) Sphingomonas spp. Abbreviations: CFU, colony forming units; MWCNT, multi-walled carbon nanotube, MWCNTs- $\mathrm{COOH}$, acidified MWCNTs.

Agar plates treated with Ag-MWCNTs yielded approximately $3 \mathrm{~mm}$ and $2 \mathrm{~mm}$ clear inhibition zones for Methylobacterium spp. and Sphingomonas spp., respectively. On the other hand, the positive control, agar plate treated with methanol - dried quickly and did not generate a clear zone of inhibition. The zone of inhibition test suggested that Ag-MWCNTs might hinder the growth of bacteria by direct contact, in which the cell membrane was ruptured and surface charge interactions between Ag-MWCNTs and the bacteria were initiated. ${ }^{27-29}$
Based on previous studies, there is a consensus that $25-40 \mu \mathrm{g} / \mathrm{mL}$ of silver nanoparticles is enough to eradicate E. coli, while $12.5-25 \mu \mathrm{g} / \mathrm{mL}$ is sufficient to eliminate S. aureus. ${ }^{8,10,24,28}$ In addition, the killing efficiency has also been shown to be dependent on nanoparticle size; $6 \mu \mathrm{g} / \mathrm{mL}$ of $7 \mathrm{~nm}$ silver particles is sufficient to eradicate bacteria. Given this understanding, we hypothesized that a minute amount of silver particles - approximately $0.1-1.0 \mu \mathrm{g} / \mathrm{mL}$ of silver nanoparticles with an average diameter of approximately $5 \mathrm{~nm}$ in a $30 \mu \mathrm{g} / \mathrm{mL}$ Ag-MWCNT solution - would result 
A

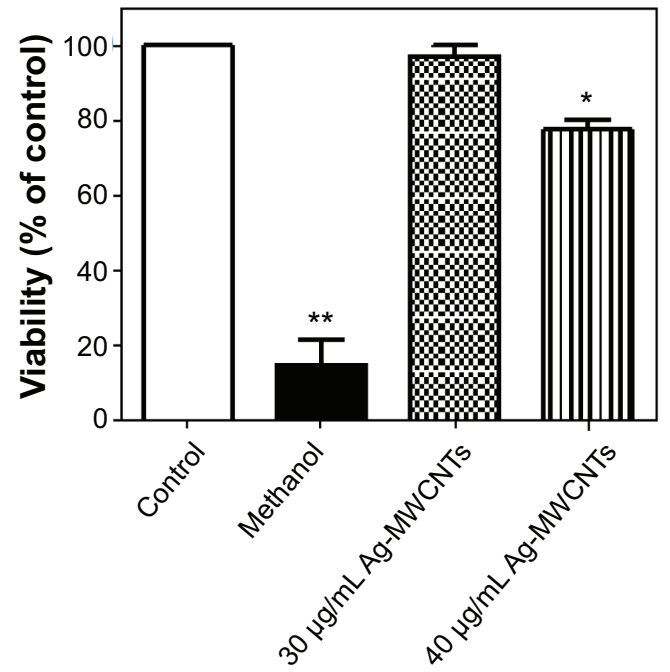

B

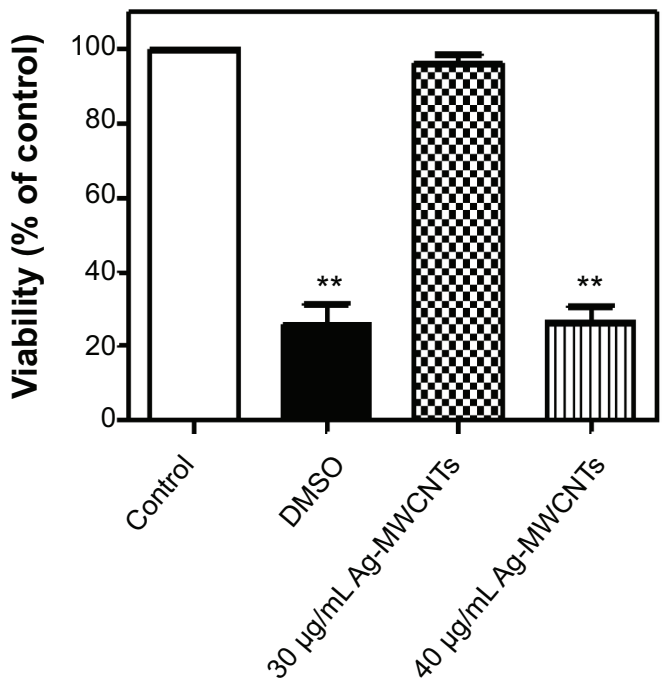

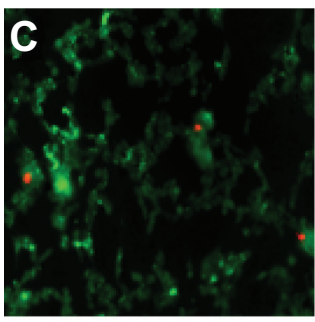
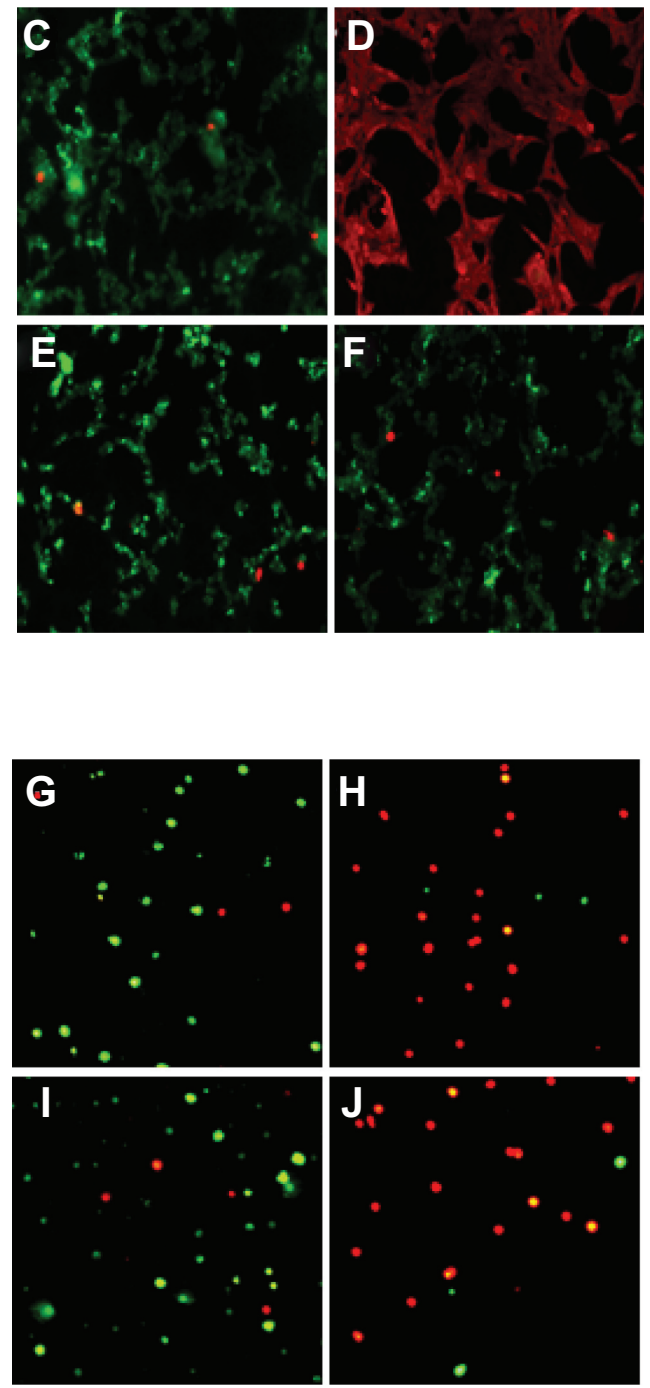

Figure 4 Cell viability assays for 30 and $40 \mu \mathrm{g} / \mathrm{mL}$ Ag-MWCNTs.

Notes: (A and B) AML 12 and human PBMCs were cultured with Ag-MWCNTs for 8 hours and their viabilities analyzed. Viability: $* P<0.05$, $* * P<0.01$, one-tailed MannWhitney $U$-test. Data are representative of three experiments. (C-F) Photomicrographs of AML 12 cells, fluorescently labeled for dead (red) and live (green) cells. (C) Control; (D) methanol; (E) $30 \mu \mathrm{g} / \mathrm{mL}$ Ag-MWCNTs; (F) $40 \mu \mathrm{g} / \mathrm{mL} \mathrm{Ag-MWCNTs.} \mathrm{(G-J)} \mathrm{Photomicrographs} \mathrm{of} \mathrm{PBMCs,} \mathrm{fluorescently} \mathrm{labeled} \mathrm{for} \mathrm{dead} \mathrm{(red)} \mathrm{and} \mathrm{live} \mathrm{(green)}$ cells. (G) Control; (H) DMSO; (I) $30 \mu \mathrm{g} / \mathrm{mL}$ Ag-MWCNTs; (J) $40 \mu \mathrm{g} / \mathrm{mL}$ Ag-MWCNTs.

Abbreviations: DMSO, dimethyl sulfoxide; MWCNT, multi-walled carbon nanotube; PBMCs, peripheral blood mononuclear cells.

in an upregulated killing efficiency when decorated onto nanotubes (Figure 3).

Finally, to determine whether Ag-MWCNTs are biocompatible at concentrations of antibacterial potency, we performed cytotoxicity tests evaluating the effect of AgMWCNTs on mammalian cells (Figure 4). Both 30 and $40 \mu \mathrm{g} / \mathrm{mL}$ Ag-MWCNTs, which exhibited antibacterial efficacy against Methylobacterium spp. and Sphingomonas spp., were cultured with AML 12 mouse liver hepatocytes; liver hepatocytes were chosen as a model to reflect the initial absorption and deposition of nanomaterials in the liver in vivo. In addition, human PBMCs were also treated with Ag-MWCNTs to give a broad understanding of their blood compatibility and immunogenicity. The trypan blue exclusion assay and LIVE/DEAD viability/cytotoxicity assay were chosen for this study due to the solubility of the reduced product in culture medium and the interference due to the MWCNTs when using 3-(4,5-dimethylthiazol-2-yl)2,5-diphenyltetrazolium bromide (MTT)-based reduction assays. ${ }^{29,30}$ About $10 \%$ of suspended Ag-MWCNTs in culture media were found in aggregates and precipitated within 6-8 hours post-introduction to the wells. 
Treatment of AML 12 cells with both 30 and $40 \mu \mathrm{g} / \mathrm{mL}$ Ag-MWCNTs showed comparable cytotoxicity to that of the negative control; treatment of cells with $40 \mu \mathrm{g} / \mathrm{mL}$ Ag-MWCNTs did show a visible increased level of cytotoxicity. Also, the addition of methanol in the positive control eliminated most of the bacteria cells (Figure 4A). Representative images of calcein AM-stained live cells (green) and ethidium homodimer-stained dead cells (red) are shown in Figure 4C-F. The treatment of human PBMCs with Ag-MWCNTs, however, showed a visibly different result. While human PBMCs treated with $30 \mu \mathrm{g} / \mathrm{mL}$ of Ag-MWCNTs maintained a live cell percentage statistically comparable to that of the negative control, those cultured with $40 \mu \mathrm{g} / \mathrm{mL}$ of Ag-MWCNTs showed a significantly decreased live cell percentage that was similar to that of the positive control (Figure 4B). Representative images of fluorescently labeled live and dead human PBMCs are displayed in Figure 4G-J. Previous cytotoxicity studies on silver nanoparticles evaluated the allowable amount of particles to eukaryotic cells from 10 to $100 \mu \mathrm{g} / \mathrm{mL}$. There has been no consensus, however, on the maximum amount of silver nanoparticles allowable for use in human trials. In this study, the amount of silver nanoparticles included in the $30 \mu \mathrm{g} / \mathrm{mL}$ of Ag-MWCNTs was estimated as $0.4 \mu \mathrm{g} / \mathrm{mL}$ on average that was regarded as biocompatible to the mammalian cells, as reported in previous studies. ${ }^{31-33}$ While we were not certain as to why $40 \mu \mathrm{g} / \mathrm{mL}$ of Ag-MWCNTs showed significant toxicity to the human PBMCs, we hypothesized that the nonattachment of PBMCs to the bottom of culture plates might have increased the likelihood of Ag-MWCNT contact during culture.

It is also interesting to note that the Ag-MWCNTs showed cytotoxicity only toward bacteria at $30 \mu \mathrm{g} / \mathrm{mL}$. In light of a previous report, ${ }^{11}$ which states that eukaryotic cells (eg, mammalian cells) require a higher concentration of silver nanomaterials to induce cytotoxicity than that required by prokaryotic cells (eg, bacteria) due to their increased complexity in function and increased size, our results are not surprising. In essence, Ag-MWCNTS effectively kill bacterial cells while exhibiting no significant cytotoxicity on mammalian cells.

Detailed toxicity studies of silver nanoparticles with a variety of cell types under different culture conditions are potential future studies, which may shed light on the mechanism of Ag-MWCNT interaction with cells. It should be noted, however, that our work only concerns the direct contact between Ag-MWCNTs and cells in vitro. Future work on in vivo validation of our hybrid nanostructures would be helpful towards recognizing potential toxicity and antibacterial function in clinical applications.

\section{Conclusion}

In this study, we suggested a simple method for the preparation of MWCNTs decorated with Ag nanoparticles, which may increase the antibacterial activity of nanomaterials and may minimize the potential uncontrolled absorption of silver nanoparticles in the body. We demonstrated that $30 \mu \mathrm{g} / \mathrm{mL}$ of synthesized Ag-MWCNTs yielded an efficient level of antibacterial activity against Methylobacterium spp. and Sphingomonas spp. with negligible cytotoxicity to mammalian liver cells. While Ag-MWCNTs will require significant technical advancements as well as biosafety assessments for expansion towards the commercial sector, we anticipate that the use of ethanol as a reducing agent may help in the production of environmentally friendly and inexpensive Ag-MWCNTs.

\section{Acknowledgments}

The authors thank Dr Taeho Kim at Seoul National University for his assistance with TEM. This research was supported by the Basic Science Research Program through the National Research Foundation of Korea (NRF) funded by the Ministry of Science, ICT and Future Planning (no 2008-0061891) and by the Basic Science Research Program through the NRF funded by the Ministry of Education (no 2013R1A1A1012653).

\section{Disclosure}

The authors report no conflicts of interest in this work.

\section{References}

1. Park JH, Yoon KY, Na H, et al. Fabrication of a multi-walled carbon nanotube-deposited glass fiber air filter for the enhancement of nano and submicron aerosol particle filtration and additional antibacterial efficacy. Sci Total Environ. 2011;409(19):4132-4138.

2. Hajipour MJ, Fromm KM, Ashkarran AA, et al. Antibacterial properties of nanoparticles. Trends Biotechnol. 2012;30(10):499-511.

3. Demling RH, DeSanti L. Effects of silver on wound management. Wounds. 2001;13(1 Suppl A): 1-15.

4. Lansdown A. Silver in health care: antimicrobial effects and safety in use. Curr Probl Permatol. 2006;33:19-34.

5. Chen X, Schluesener HJ. Nanosilver: a nanoproduct in medical application. Toxicol Lett. 2008;176(1):1-12.

6. Singh M, Singh S, Prasad S, Gambhir IS. Nanotechnology in medicine and antibacterial effect of silver nanoparticles. Dig J Nanomater Biostruct. 2008;3(3):115-122.

7. Ping L, Juan L, Changzhu W, Qingsheng W, Jian L. Synergistic antibacterial effects of $\beta$-lactam antibiotic combined with silver nanoparticles. Nanotechnology. 2005;16(9):1912-1917. 
8. Martínez-Castañón GA, Niño-Martínez N, Martínez-Gutierrez F, Martínez-Mendoza JR, Ruiz F. Synthesis and antibacterial activity of silver nanoparticles with different sizes. J Nanopart Res. 2008;10(8): 1343-1348.

9. Lok CN, Ho CM, Chen R, et al. Silver nanoparticles: partial oxidation and antibacterial activities. J Biol Inorg Chem. 2007;12(4):527-534.

10. Marambio-Jones C, Hoek EMV. A review of the antibacterial effects of silver nanomaterials and potential implications for human health and the environment. J Nanopart Res. 2010;12(5):1531-1551.

11. Wijnhoven SWP, Peijnenburg WJGM, Herberts CA, et al. Nanosilver - a review of available data and knowledge gaps in human and environmental risk assessment. Nanotoxicology. 2009;3(2):109-138.

12. Ajayan PM. Nanotubes from carbon. Chem Rev. 1999;99(7): 1787-1800.

13. Kang S, Mauter MS, Elimelech M. Physicochemical determinants of multiwalled carbon nanotube bacterial cytotoxicity. Environ Sci Technol. 2008;42(19):7528-7534.

14. Ma PC, Tang BZ, Kim JK. Effect of CNT decoration with silver nanoparticles on electrical conductivity of CNT-polymer composites. Carbon. 2008;46(11):1497-1505.

15. Ghalkhani M, Shahrokhian S, Ghorbani-Bidkorbeh F. Voltammetric studies of sumatriptan on the surface of pyrolytic graphite electrode modified with multi-walled carbon nanotubes decorated with silver nanoparticles. Talanta. 2009;80(1):31-38.

16. Xin F, Li L. Decoration of carbon nanotubes with silver nanoparticles for advanced CNT/polymer nanocomposites. Compos Part A Appl Sci Manuf. 2011;42(8):961-967.

17. Shi Y, Liu Z, Zhao B, et al. Carbon nanotube decorated with silver nanoparticles via noncovalent interaction for a novel nonenzymatic sensor towards hydrogen peroxide reduction. J Electroanal Chem (Lausanne Switz). 2011;656(1-2):29-33.

18. Avilés F, Cauich-Rodríguez JV, Moo-Tah L, May-Pat A, VargasCoronado R. Evaluation of mild acid oxidation treatments for MWCNT functionalization. Carbon. 2009;47(13):2970-2975.

19. Jiang ZJ, Liu CY, Liu Y. Formation of silver nanoparticles in an acid-catalyzed silica colloidal solution. Appl Surf Sci. 2004;233(1-4): $135-140$.

20. Ebbesen TW, Hiura H, Bisher ME, Treacy MMJ, Shreeve-Keyer JL, Haushalter RC. Decoration of carbon nanotubes. Adv Mater. 1996;8(2): 155-157.

21. Neelgund GM, Oki A. Deposition of silver nanoparticles on dendrimer functionalized multiwalled carbon nanotubes: synthesis, characterization and antimicrobial activity. J Nanosci Nanotechnol. 2011;11(4):3621-3629.
22. Yuan W, Jiang G, Che J, et al. Deposition of silver nanoparticles on multiwalled carbon nanotubes grafted with hyperbranched poly(amidoamine) and their antimicrobial effects. J Phys Chem C Nanomater Interfaces. 2008;112(48):18754-18759.

23. Gupta S, Farmer J. Multiwalled carbon nanotubes and dispersed nanodiamond novel hybrids: microscopic structure evolution, physical properties, and radiation resilience. J Appl Phys. 2011;109(1):014314-014315.

24. Mohan R, Shanmugharaj AM, Sung Hun R. An efficient growth of silver and copper nanoparticles on multiwalled carbon nanotube with enhanced antimicrobial activity. J Biomed Mater Res B Appl Biomater. 2011;96(1):119-126.

25. Rangari VK1, Mohammad GM, Jeelani S, et al. Synthesis of Ag/ CNT hybrid nanoparticles and fabrication of their nylon-6 polymer nanocomposite fibers for antimicrobial applications. Nanotechnology. 2010;21(9):095102.

26. Prodana M, Ionita D, Ungureanu C, Bojin D, Demetrescu I. Enhancing antibacterial effect of multiwalled carbon nanotubes using silver nanoparticles. Dig J Nanomater Biostruct. 2011;6(2):549-556.

27. Murugan E, Vimala G. Effective functionalization of multiwalled carbon nanotube with amphiphilic poly(propyleneimine) dendrimer carrying silver nanoparticles for better dispersability and antimicrobial activity. J Colloid Interface Sci. 2011;357(2):354-365.

28. Barani H, Montazer M, Samadi N, Toliyat T. Nano silver entrapped in phospholipids membrane: synthesis, characteristics and antibacterial kinetics. Mol Membr Biol. 2011;28(4):206-215.

29. Wörle-Knirsch J, Pulskamp K, Krug H. Oops they did it again! Carbon nanotubes hoax scientists in viability assays. Nano Lett. 2006;6(6): 1261-1268.

30. Yang H, Liu C, Yang D, Zhang H, Xi Z. Comparative study of cytotoxicity, oxidative stress and genotoxicity induced by four typical nanomaterials: the role of particle size, shape and composition. $J \mathrm{Appl}$ Toxicol. 2009;29(1):69-78.

31. Hussain SM, Hess KL, Gearhart JM, Geiss KT, Schlager JJ. In vitro toxicity of nanoparticles in BRL $3 \mathrm{~A}$ rat liver cells. Toxicol In Vitro. 2005;19(7):975-983.

32. Ahamed M, Alsalhi MS, Siddiqui MK. Silver nanoparticle applications and human health. Clin Chim Acta. 2010;411(23-24):1841-1848.

33. AshaRani P, Low Kah Mun G, Hande MP, Valiyaveettil S. Cytotoxicity and genotoxicity of silver nanoparticles in human cells. ACS Nano. 2009;3(2):279-290.
International Journal of Nanomedicine

\section{Publish your work in this journal}

The International Journal of Nanomedicine is an international, peerreviewed journal focusing on the application of nanotechnology in diagnostics, therapeutics, and drug delivery systems throughout the biomedical field. This journal is indexed on PubMed Central,

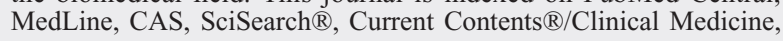

\section{Dovepress}

Journal Citation Reports/Science Edition, EMBase, Scopus and the Elsevier Bibliographic databases. The manuscript management system is completely online and includes a very quick and fair peer-review system, which is all easy to use. Visit http://www.dovepress.com/ testimonials.php to read real quotes from published authors. 